Policy ANd Practice Brief

\title{
Improving the function of a high obesity program: Findings from community-engaged Mississippi Delta focus groups
}

\author{
Erin M. King, ${ }^{a}{ }^{*}$ Connie Baird-Thomas, ${ }^{b}$ Angela Robertson, ${ }^{\mathrm{c}}$ \\ Masey Smith, ${ }^{\mathrm{d}}$ and David R. Buys ${ }^{\mathrm{e}}$ \\ Mississippi State University
}

Submitted July 15, 2021 / Published online September 14, 2021

Citation: King, E. M., Baird-Thomas, C., Robertson, A., Smith, M., \& Buys, D. R. (2021).

Improving the function of a high obesity program: Findings from community-engaged

Mississippi Delta focus groups. Journal of Agriculture, Food Systems, and Community Development, 10(4), 123-126. https://doi.org/10.5304/jafscd.2021.104.012

Copyright (C) 2021 by the Authors. Published by the Lyson Center for Civic Agriculture and Food Systems. Open access under CC-BY license.

\begin{abstract}
In this policy and practice brief, Mississippi State University Extension Services applies a coalitiondriven approach to addressing the prevalence of obesity in communities in the Mississippi Delta through its High Obesity Program, funded by the Centers for Disease Control and Prevention (CDC). Focus groups were conducted with coali-
\end{abstract}

a* Corresponding author: Erin M. King, MPH, MS, Graduate Research Assistant, Department of Food Science, Nutrition and Health Promotion; P.O. Box 9805; Mississippi State University, MS 39762 USA; +1-256-702-8132; emk234@msstate.edu

b Connie Baird-Thomas, Ph.D., Associate Director, Social Science Research Center; Mississippi State Univerity; 1 Research Boulevard, Suite 103; Starkville, MS 39759 USA; connie.baird-thomas@ssrc.msstate.edu

c Angela Robertson, Ph.D., Associate Director, Social Science Research Center; 1 Research Boulevard, Suite 103; Starkville, MS 39759 USA; angela.robertson@ssrc.msstate.edu tion members from six counties to evaluate efforts by this program. The evaluation team used content and thematic analysis to report on coalition activities. Some of the barriers coalition members identified were limited access to healthy foods and the need for more assistance from program staff. Action items were developed and implemented in response to focus group feedback. These items

\footnotetext{
d Masey Smith, MPA, Program Manager, Department of Food Science, Nutrition and Health Promotion; P.O. Box 9805; Mississippi State University, MS 39762 USA; msmith@,ext.msstate.edu

e David R. Buys, Ph.D., MSPH, CPH, FGSA, State Health Specialist and Associate Professor, Department of Food Science, Nutrition and Health Promotion; P.O. Box 9805; Mississippi State University, MS 39762 USA; david.buys@msstate.edu
}

\section{Funding Disclosure}

Funding for AIM for $\mathrm{CHangE}$ was provided by the Centers for Disease Control and Prevention High Obesity Program by cooperative agreement NU58DP006572. No copyrighted materials were used in this article. 
included enhanced communication tools and coalition trainings. This evaluation brief describes some of the common challenges in coalition building and innovative ways to improve them. Our focus group findings are also valuable to public health scientists and practitioners working in rural communities.

\section{Keywords}

Obesity, Nutrition, Physical Activity, Focus

Groups, Rural Health, Health Equity

\section{Introduction}

Food insecurity is the lack of resources to access healthy foods (Dhurandhar, 2016). Ironically, food insecurity and obesity often co-occur. It seems logical to assume that food insecurity would cause a deficit in food consumption and reduce obesity. However, economic factors can limit the ability to purchase nutritious foods, which leads to conditions of overweight and obesity (Dhurandhar, 2016). The Mississippi Delta is a prime example of this paradox of food insecurity and obesity, with 17 of the 19 counties experiencing at least 15-19\% food insecurity and eight of the 19 counties facing obesity rates greater than 40\% (Feeding America, n.d.; Mississippi State University Extension, n.d.). The highly agricultural nature of this region also limits community connections due to low population density (Whitley, 2013). Low social capital influences rural residences' ability to network and access healthy foods that are unavailable through retail outlets (Whitley, 2013).

AIM for CHangE (Advancing, Inspiring, Motivating for Community Health through Extension) was funded through Mississippi State University (MSU) Extension's CDC-High Obesity Program to reduce obesity and food insecurity in Mississippi counties with obesity rates greater than $40 \%$ (Mississippi State University, n.d.; Murriel et al., 2020). AIM for CHangE works to reduce obesity by improving existing nutrition and physical activity-related projects and establishing new programs. Reducing obesity in these counties is primarily achieved through (1) increasing access to healthier foods; and (2) promoting physical activity (Baird-Thomas et al., 2020). In this policy and practice brief, AIM for $\mathrm{CHangE}$ team members evaluate the strategies used to implement projects designed and carried out by county-based coalitions. Coalitions were composed of stakeholders that represent multiple sectors within their communities and individuals that are interested in improving health outcomes in their county (National Association of County and City Health Officials [NACCHO], n.d.). Coalitions were able to apply for funding through AIM for CHangE. Supported projects focused on improving nutrition, increasing fruit and vegetable consumption, and encouraging active living or increasing physical activity.

\section{Evaluation Approach}

This report describes efforts to evaluate the effectiveness of practices and procedures used by AIM for $\mathrm{CHangE}$ to reduce obesity and clarify community needs. There were 10 approved projects in the early stages of implementation during focus groups. Focus groups were facilitated by the programs' evaluation team: two research scientist and a graduate research assistant (Baird-Thomas et al., 2020). The interview guide, available from the corresponding author upon request, stimulated responses on the development of coalitions, level of support provided by AIM for $\mathrm{CHangE}$ agents, and perceived barriers to access healthy foods and physical activity (Baird-Thomas et al., 2020). Each focus group participant was offered a US $\$ 25$ gift card to a local retailer (Baird-Thomas et al., 2020). Focus group sessions were recorded, transcribed, and analyzed for reporting to the CDC. Facilitators utilized thematic analysis to identify categories and concepts from focus groups (Braun \& Clarke, 2006). Once researchers came to a consensus on specified themes, results were documented.

\section{Findings and Collaborations}

The findings in this report will focus on programmatic functions and food access. Six focus groups were conducted with 39 coalition members (BairdThomas et al., 2020). Focus group participants' ages ranged from 38 to 79 years old and participants identified as either White or African American (Baird-Thomas et al., 2020). Quotations from focus group participants can be found in Table 1.

Focus group participants requested clarity from staff on guidelines to identify projects eligible 
Table 1. AIM for CHangE Focus Group Findings and Themes

\begin{tabular}{ll}
\hline Themes & Focus Group Quotations \\
\hline Agent Competency & $\begin{array}{l}\text { He gave us a lot of information on how to train us, how to get the statements. He gave } \\
\text { us a booklet on how to get that written so that it could be accepted. }\end{array}$ \\
\hline $\begin{array}{l}\text { Group dynamics and expanding } \\
\text { funding }\end{array}$ & $\begin{array}{l}\text { money. How many organizations or how many communities we had in the room, we } \\
\text { tried to be equitable with it. ... }\end{array}$ \\
\hline $\begin{array}{l}\text { Implementation of projects and } \\
\text { nutrition standards }\end{array}$ & $\begin{array}{l}\text { We serve about } 80 \text { people a day at the soup kitchen. Or, more it depends on the } \\
\text { weather and time. ... I tell them how to eat foods that, less sodium.... We were able } \\
\text { to get a stove, a commercial stove. . . But now everything is growing, and it's been a } \\
\text { blessing. }\end{array}$ \\
\hline
\end{tabular}

for funding (Baird-Thomas et al., 2020). Coalition members provided encouraging feedback about collaborating with AIM for CHangE agents (BairdThomas et al., 2020). Focus group findings revealed that coalitions used their allotted grant funding in communities with the greatest need. Our administrative staff was pleased to observe the process community members used to select projects for funding. However, coalition members did not choose other relevant opportunities due to limited funding.

Coalition members revealed that access to food sources and healthy food outlets were limited (Baird-Thomas et al., 2020). Participants reported traveling on average 10 miles to purchase groceries with full-scale grocery stores ranging from five to 60 miles away from their home (Baird-Thomas et al., 2020). Community members reported utilizing food pantries, farmers markets, and community gardens to access fresh produce and other necessities (Baird-Thomas et al., 2020). Food pantry leaders also made staff aware of the implementation of grant-funded equipment and the incorporation of nutrition guidelines when preparing meals.

\section{Lessons Learned and Responses to Implementation}

Focus groups allowed our team to better understand how our coalitions function and their barriers to improving diet quality and active living. These findings also illuminated areas for improvement in our process for disseminating and distributing collected data among coalitions. To reduce the stigmatization of utilizing food assistance programs and improve nutrition standards, AIM for $\mathrm{CHangE}$ hosted virtual trainings on food insecurity and the Choice Food Pantry Model during the summer of 2020 (End Hunger in America, n.d.). In addition to reducing obesity, our staff is implementing strategies to encourage the sustainability of coalitions after the culmination of our program. For example, we held a grant-writing workshop to teach community members the process of identifying and applying for funding opportunities in addition to AIM for $\mathrm{CHang}$ E funding. Adapting to community preferences and creating an open dialogue with our coalition members has been fundamental to our program's success thus far.

\section{Implications for Practice}

This evaluation underscored the importance of collaborating with our communities instead of using exclusively academically led approaches. Utilizing focus groups for data collection and community engagement has proven an adequate evaluation method for our program. While our long-term goal is to reduce obesity, it is paramount to our team to maintain positive and productive relationships with the communities we serve. Other community initiatives can utilize our focus group findings to develop programmatic efforts and plan for the future.

\section{Acknowledgments}

We immensely appreciate the time and dedication AIM for CHangE coalition members and Extension Agents have put into our program. We also acknowledge Mississippi State University Department of Food Science, Nutrition, and Health Promotion. 


\section{References}

Baird-Thomas, C., King, E., \& Robertson, A. (2020). Coalition focus group report: Notes from the field.

Braun, V., \& Clarke, V. (2006). Using thematic analysis in psychology. Qualitative Research in Psychology, 3(2), 77-101. https://doi.org/10.1191/1478088706qp063oa

Dhurandhar, E. J. (2016). The food-insecurity obesity paradox: A resource scarcity hypothesis. Physiology \& Behavior, 162, 88-92. http://doi.org/10.1016/j.physbeh.2016.04.025

End Hunger in America. (n.d.). Client choice food pantries. Retrieved July 2021 from https://www.endhungerinamerica.org/getting-started/client-choice-food-pantries/

Feeding America. (n.d.). Food insecurity in Mississippi before COVID-19. Retrieved July 2021 from https://map.feedingamerica.org/county/2018/overall/mississippi

Mississippi State University Extension. (n.d.). AIM for CHangE overview. http://extension.msstate.edu/content/aim-for-change-overview

Murriel, A.L, Kahin, S., Pejavara, A., \& O’Toole, T. (2020). The high obesity program: Overview of the center for disease control and prevention and cooperative extension services efforts to address obesity. Preventing Chronic Disease, 17(25), 1-6. https://doi.org/10.5888/pcd17.190235

National Association of County and City Health Officials (NACCHO). (n.d.). Partnerships and coalitions [Fact sheet]. https://www.naccho.org/uploads/downloadable-resources/Partnerships-and-Coalitions.pdf

Whitley, S. A. (2013). Changing times in rural America: Food assistance and food insecurity in food deserts. Journal of Family Social Work, 16(1), 36-52. https://doi.org/10.1080/10522158.2012.736080 